\title{
A novel approach for enhanced catalytic microwave pyrolysis of low-rank coal
}

Lei $\mathrm{Wu}^{1}$, Jun Zhou ${ }^{2,3^{*}}$, Rongrong Yang ${ }^{2}$, Tian $\mathrm{Wei}^{4}$, Qiuli Zhang ${ }^{2,3}$, Yonghui Song1,3, Yuhong $\operatorname{Tian}^{2,3}$, Xinzhe $\operatorname{Lan}^{3}$

(1. School of Metallurgical Engineering, Xi`an University of Architecture and Technology, Xi`an 710055, China; 2. School of Chemistry and Chemical Engineering, Xi`an University of Architecture and Technology, Xi`an 710055, China; 3. Research Centre of Metallurgical Engineering \& Technology of Shaanxi Province, Xi'an 710055, China; 4. State Key Laboratory of Iron \& Steel Industry Environmental Protection, Beijing 100088, China)

\section{Experimental}

\subsection{Sample}

The information of national standards in Table 1 are as follows.

(1) National Standard of P. R. China: Coke- Determination of proximate analysis (GB/T 2001-2013)

(2) National Standard of P. R. China: Determination of carbon and hydrogen in coal (GB/T 476-2008)

(3) National Standard of P. R. China: Determination of nitrogen in coal (GB/T 19227-2008)

(4) National Standard of P. R. China: Determination of total sulfur composition of coke (GB/T2286-2017)

(5) National Standard of P. R. China: Ultimate analysis of coal (GB/T 31391-2015)

\section{Results and discussion}

3.1 Pyrolysis temperature

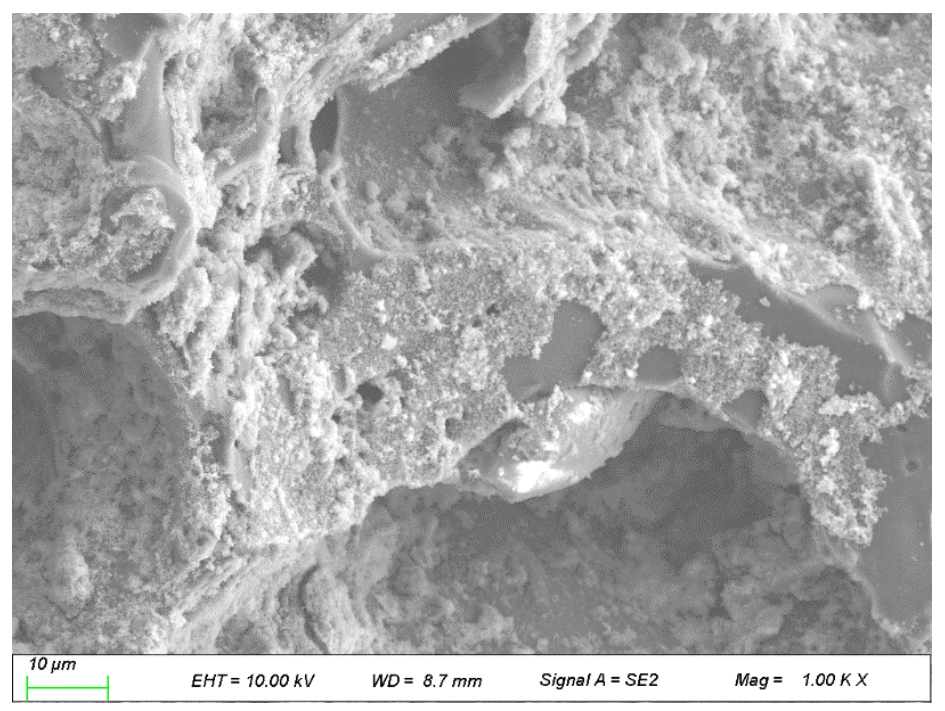


(1a)

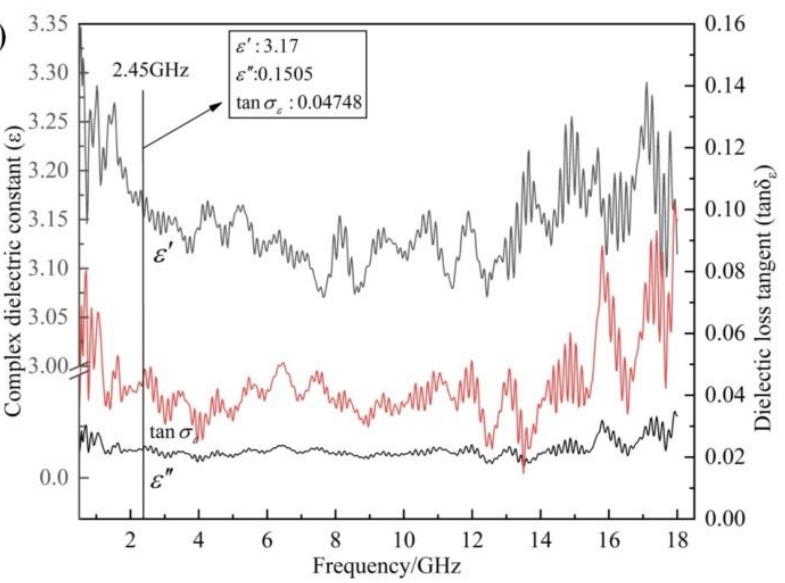

(2a)

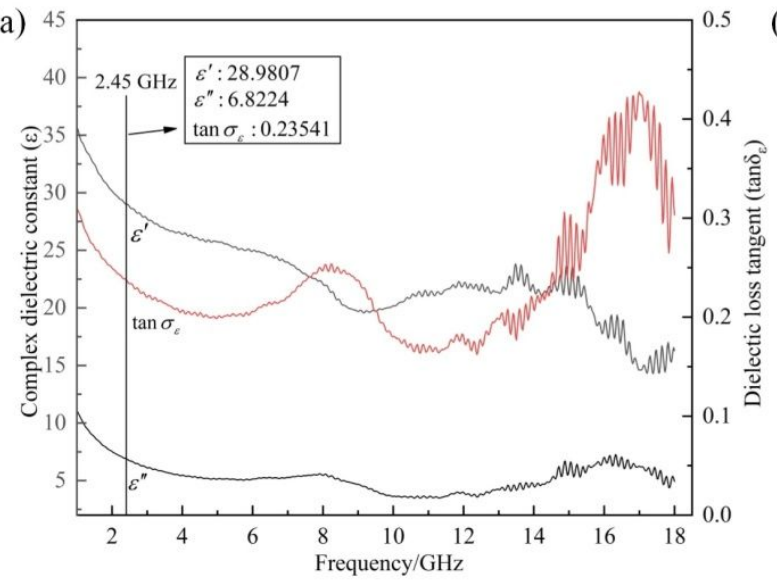

(3a)

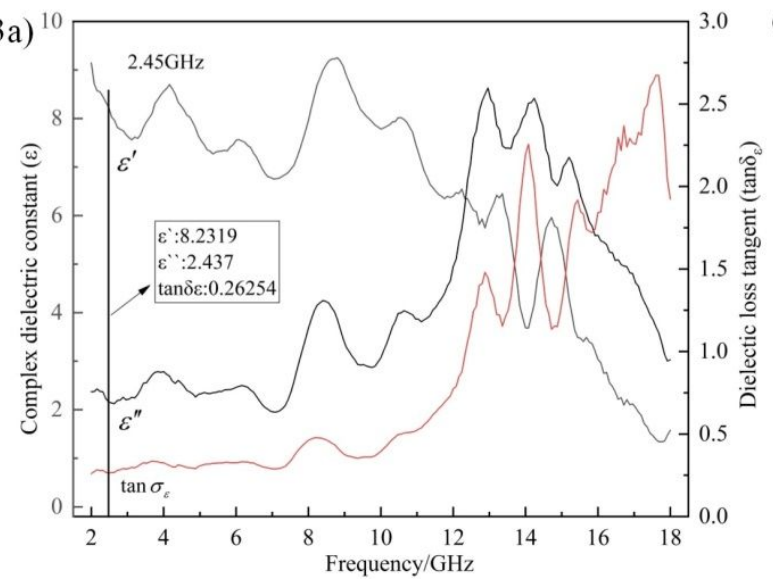

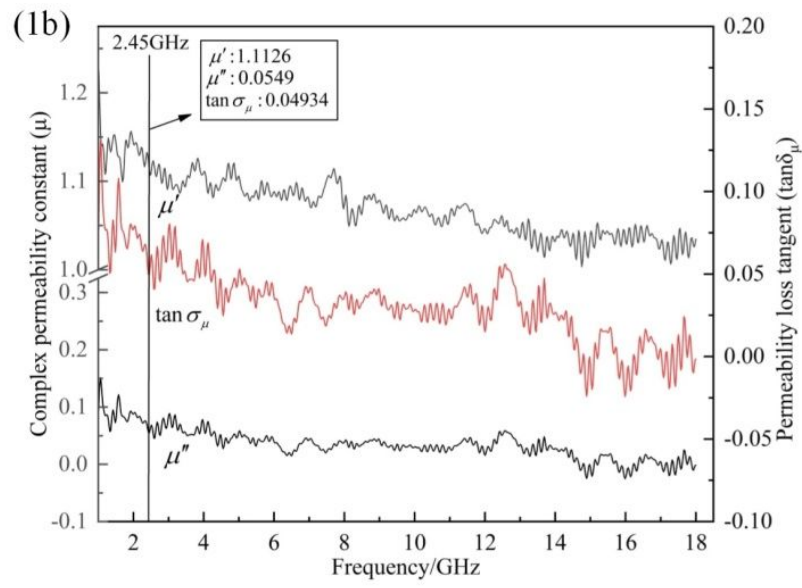

(2b)

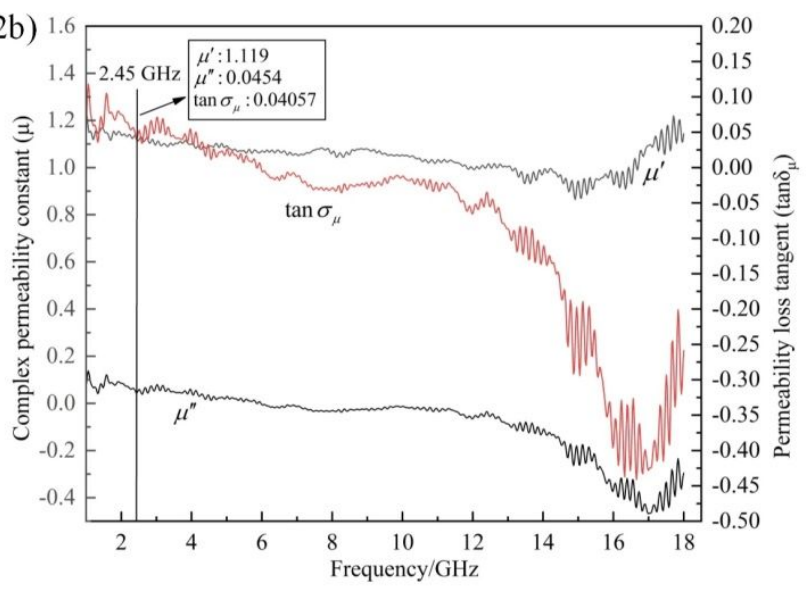

(3b)

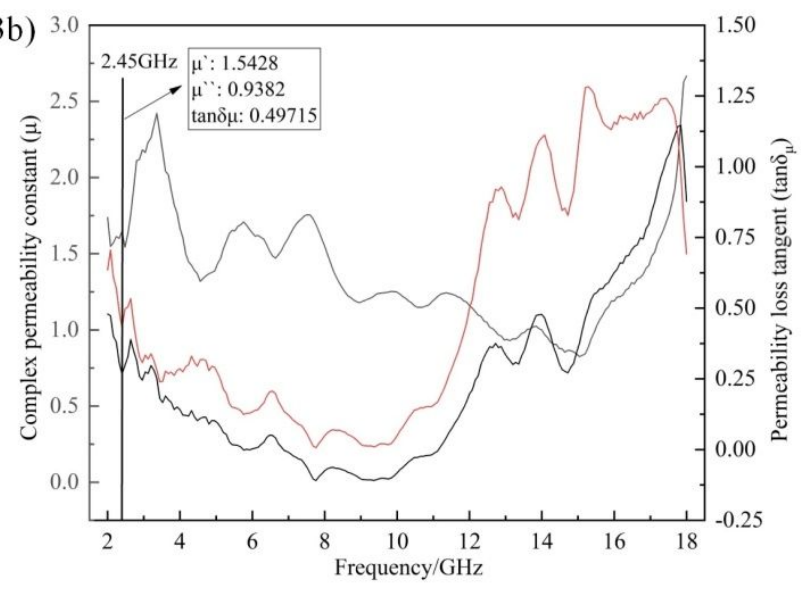

Fig. S2 Electromagnetic properties of coal (1), bluecoke (2) and $\mathrm{Fe}_{2} \mathrm{O}_{3} / \mathrm{BC}$ absorber (3) 